Article

\title{
Phenolic Compounds and Antioxidant Activity of Sprouts from Seeds of Citrus Species
}

\author{
Beatrice Falcinelli ${ }^{1}$, Franco Famiani ${ }^{1}$, Andrea Paoletti ${ }^{1}$, Sara D'Egidio ${ }^{2}$, Fabio Stagnari ${ }^{2}$, \\ Angelica Galieni ${ }^{3}$ and Paolo Benincasa ${ }^{1, * \mathbb{D}}$ \\ 1 Dipartimento di ScienzeAgrarie, AlimentariedAmbientali, Università di Perugia, Borgo XX Giugno, \\ 74-06121 Perugia, Italy; beatricefalcinelli90@gmail.com (B.F.); franco.famiani@unipg.it (F.F.); \\ andrea.paoletti1@gmail.com (A.P.) \\ 2 Facoltà di Bioscienze e Tecnologie Agro-AlimentariAmbientali, Università di Teramo, 64100 Teramo, Italy; \\ saradegidio@hotmail.com (S.D.); fabio.stagnari@unite.it (F.S.) \\ 3 Consiglio per la Ricerca in Agricoltura e l'Analisidell'Economiaagraria, Centro di Ricerca per Orticoltura e \\ Florovivaismo (CREA-OF), Monsampolo del Tronto, 63077 Ascoli Piceno, Italy; angelica.galieni@crea.gov.it \\ * Correspondence: paolo.benincasa@unipg.it; Tel.: +39-075-5856325
}

Received: 18 December 2019; Accepted: 27 January 2020; Published: 30 January 2020

check for updates

\begin{abstract}
Seeds from Citrus species represent a relevant by-product of the juice industry and a potential source of bioactive compounds such as phenols and other antioxidants. Sprouting could be an intriguing idea to enhance the content of these compounds, as explored for other fruittree species. In this experiment, the sprouting performance, the concentration of total phenols and phenolic acids, and the antioxidant activity of seeds and sprouts were evaluated for bitter orange (Citrus aurantium $\mathrm{L}$. seedlings), blonde orange (Citrus sinensis (L.) Osbeck cv.Biondocomune), sweet orange (Citrus sinensis (L.) Osbeck seedlings), lemon (Citrus limon (L.) Osbeck cv.Femminello), and mandarin (Citrus reticulata Blanco cv.Tardivo di Ciaculli). The germination was high for all genotypes except for mandarin, but it took 4-8 weeks. Sprouts did not differ among genotypes for size and generally had hard consistency of cotyledons and a bitter taste. The concentrations of total phenols and phenolic acids of seeds and sprouts varied with the genotype, while the antioxidant activity was not statistically different among treatments. Sprouting increased both the concentration of phenolic compounds and antioxidant activity but no correlation was found between them, suggesting that other antioxidants, besides phenols, are present. Given the slow germination and the bitter taste, Citrus sprouts appear unsuitable for homemade production aimed at direct consumption, while they may have perspectives for extraction of food additives, cosmetics, and pharmaceutics.
\end{abstract}

Keywords: phytochemicals; phenolic acids; by-product; germination

\section{Introduction}

Fruits from Citrus species represent a worldwide commodity of over 100 million metric tons per year [1]. Around $80 \%$ of fruit production is used in the juice industry, with a by-product of $55 \%$ in weight represented by peels and seeds [1]. Citrus seeds are reported to contain limonoids (the typical Citrus triterpenoids) and phenolic compounds, such as phenolic acids and flavonoids, tocopherols, and carotenoids, the effects of which on human health are well known [1,2]. Caffeic, $p$-coumaric, and ferulic acids are among the main representative phenolic acids in Citrus seed extracts [2]; however, the phenolic profile composition strictly depends on both genotyping and environmental factors [1]. This opens perspectives for exploiting these by-products as a source of bioactive compounds for food additives and supplements, cosmetics, and pharmaceutics [1-3]. Since the consumption of Citrus seeds in human nutrition is hampered mainly by the woody texture and the astringent and bitter taste, 
an intriguing idea could be represented by the use of seeds for sprouting, as recently proposed for other fruit tree species [4,5]. Sprouting is a new trend in healthy food and nutraceutics because it provides edible seedlings with reduced antinutrient and increased phytochemical contents compared to seeds.To this purpose, a significant body of literature has been developed on herbaceous species intended for sprout production [6], while the effects of germination on the biochemical composition of tree species have been scarcely investigated. Higher total phenolic content in sprouts as compared to seeds was observed, for example, in pomegranate [4] and olive [5]. It is noteworthy that Citrus seeds are considered recalcitrant, with serious storage problems due to their sensitivity to either chilling or desiccation. Moreover, their low and slow germination may represent a main limitation for sprouting purposes, especially for homemade production, where the consumer requires a feasible, short, and cheap way to obtain sprouts. However, the germination of Citrus species is reported to be high when seeds are sown immediately after separation from the fruit pulp [7-11]. Finally, the germination performance and phytochemical content of Citrus sprouts is expected to depend on the genotype. As for other agricultural species, breeding programs over the last decades have focused on productivity and fruit taste, often to the detriment of plant tolerance to biotic and abiotic stresses, which is related to the content of those secondary metabolites that also represent healthy compounds in the human diet.

Thus, the aim of this work was to obtain sprouts from different Citrus genotypes and compare them for germination performance, concentration of phenolic compounds with a focus on phenolic acids, and antioxidant activity.

\section{Materials and Methods}

\subsection{Plant Material and Sprouting}

The seeds used in this experiment belong to bitter orange (Citrus aurantium L. seedlings), blonde orange (Citrus sinensis (L.) Osbeck cv.Biondo commune), sweet orange (Citrus sinensis (L.) Osbeck seedlings), lemon (Citrus limon (L.) Osbeck cv.Femminello), and mandarin (Citrus reticulata Blanco cv.Tardivo di Ciaculli).

Citrus seeds were obtained from ripe fruits produced by trees cultivated in the urban park "Parco d'Orleans" in Palermo, Sicily, Italy in 2018. Seeds were separated from fruits by hand and washed with tap water. After removing pulp residues, an additional washing with distilled water was performed. The amount of seeds needed for any replicate in any experiment was taken randomly from the seed bulk obtained. Some seeds from each genotype were frozen in liquid nitrogen and stored at $-80^{\circ} \mathrm{C}$ until chemical analysis. A preliminary germination test was performed with three replicates of 100 seeds per each of the five genotypes to determine the total germination percentage $(\mathrm{G})$, the mean germination time (MGT), and the time to reach 50\% germination (TG50). Seeds were immediately sown in plastic trays containing sterile paper laid over sterile cotton wetted with distilled water. The trays were covered by a drilled top in order to maintain the air circulation while preventing dehydration. The trays were incubated in a growth chamber at $20{ }^{\circ} \mathrm{C}$ in a light:dark regime of $12: 12 \mathrm{~h}$.

The number of germinated seeds was recorded daily for 8 weeks from the start of the incubation. MGT was calculated according to Ellis and Roberts [12].

The sprouting experiment was carried out with the same procedure and conditions used for the germination test. Treatments (i.e., the five genotypes) were laid down according to a completely randomized design with three replicates (trays). The ready-to-eat stage of sprouts was assumed to be between the complete cotyledon expansion and just before the emission of the first true leaf, according to Falcinelli et al. [4,5]. Since germination time varied among and within each genotype, sprouts were collected time by time whenever they reached the ready-to-eat stage. Fresh and dry weights were measured on a subsample of 10 sprouts per replicate. The rest of the sprouts of each replicate were lyophilized, finely homogenized, and stored at room temperature until the analysis. 


\subsection{Chemicals}

2,2'-Azinobis-(3-ethyl-benzothiazoline-6-sulfonic acid) (ABTS), hydrochloric acid, methanol (high-performance liquid chromatography (HPLC) grade), acetonitrile (HPLC grade), and ethyl acetate were purchased from Carlo Erba (Milan, Italy). Sodium carbonate was provided by Panreac (Barcelona, Spain). Folin-Ciocalteau reagent, sodium hydroxide, gallic acid (GA), vanillic acid (VA), caffeic acid (CaA), $p$-coumaric acid ( $p$-CA), and trans-ferulic acid (FA) were purchased from Sigma-Aldrich (St. Louis, MO, USA). All standards were prepared as stock solution at $1 \mathrm{mg} \mathrm{mL}^{-1}$ in methanol and stored at $-20^{\circ} \mathrm{C}$ in darkness conditions.

\subsection{Samples Extraction}

The extraction of free phenolic acids (PAs) was achieved following the procedure of Benincasa et al. [13] with some modifications. Samples of $0.5 \mathrm{~g}$ were mixed and sonicated with $5 \mathrm{~mL}$ of methanol for $30 \mathrm{~min}$ at a temperature of $<40^{\circ} \mathrm{C}$. After sonication, samples were centrifuged at $2000 \times \mathrm{g}$ for $10 \mathrm{~min}$ and the supernatant was removed. Two milliliters of each extract were evaporated to dryness under a gentle flow of nitrogen at $30^{\circ} \mathrm{C}$, redissolved in $0.5 \mathrm{~mL}$ of methanol, and filtered through cellulose-acetate $0.45 \mu \mathrm{m}$ filters. All the extraction procedures were performed under dim light to avoid sample degradation by photo-oxidation.

\subsection{Total Phenolic Concentration (TPC)}

The TPC of the soluble phenolic fraction was evaluated using the Folin-Ciocalteaureagent following a method adapted from Singleton and Rossi [14]. The extract $(0.1 \mathrm{~mL})$ was added to $0.5 \mathrm{~mL}$ of Folin-Ciocalteau reagent; after $1 \mathrm{~min}, 1.5 \mathrm{~mL}$ of a $20 \% \mathrm{Na}_{2} \mathrm{CO}_{3}$ solution was added and then deionized water up to $10 \mathrm{~mL}$ final volume. Solutions were maintained at room temperature under dark conditions for $120 \mathrm{~min}$ and then centrifuged at $4000 \mathrm{rpm}$ for $10 \mathrm{~min}$. TPC was determined at $765 \mathrm{~nm}$ using a Perkin Elmer Lambda Bio 20 spectrophotometer (Perkin-Elmer, Waltham, MA, USA). Gallic acid standard solutions were used to calibrate the method and the results are expressed as milligrams of gallic acid equivalents (GAE) per gram of dry weight (DW).

\subsection{HPLC Analysis: Chromatographic Conditions}

Identification and quantification of the PAs were carried out according to the method previously described by Benincasa et al. [13]. The extracts $(10 \mu \mathrm{L})$ were analyzed by using an HPLC system consisting of an "Alliance" (Waters, Milford, MA, USA) equipped with a Waters 2695 separation module connected to a Waters 2996 photodiode array detector (PDA). The compound separation was achieved on a Kinetex C18 column $(250 \times 4.6 \mathrm{~mm}$ ID, $5 \mu \mathrm{m}$; Phenomenex, Torrance, CA, USA), thermostated at $25^{\circ} \mathrm{C}$, at a flow rate of $1 \mathrm{mLmin}^{-1}$ using a linear gradient obtained by (A) acetonitrile and (B) water/acetic acid (99:1 v/v) from 10\% to 70\% solvent A for $30 \mathrm{~min}$ and subsequent return to initial composition in $4 \mathrm{~min}$, achieving mobile phase stabilization for $10 \mathrm{~min}$. The eluted peaks were detected at $260 \mathrm{~nm}$ for VA and $325 \mathrm{~nm}$ for CaA, FA, and $p$-CA. Identification of PAs was based on their retention times and UV-VIS spectra compared with those of standard solutions. The calibration curves (i.e., the peak area versus concentration) were linear in the range of concentration between 1 and $50 \mathrm{mg} \mathrm{L}^{-1}$. The lines of regression calculated were used for quantitative analysis of PAsin the extracts; the results are expressed as $\mu \mathrm{g} \mathrm{g}^{-1} \mathrm{DW}$. Accuracy, evaluated by means of recovery of PAs added to samples, was found to be more than $90 \%$ for all the PAs detected. The within-assay precision (repeatability) never exceeded $8 \%$. Limits of detection, set on the basis of the signal-to-noise ratio $(\mathrm{S} / \mathrm{N})$ of 3, were $0.10 \mu \mathrm{g} \mathrm{g}^{-1}$ for CaA, $p$-CA, and FA and $0.25 \mu \mathrm{g} \mathrm{g}^{-1}$ for VA.

\subsection{Antioxidant Activity}

For the antioxidant activity determination, Trolox equivalent antioxidant capacity (TEAC) with ABTS and 2,2-diphenyl-1picrylhydrazyl (DPPH) methods were utilized. The TEAC/ABTS assay 
was determined as described by Masaldan and Iyer [15], while the DPPH antioxidant potential was measured according to the method described by Brand-Williams et al. [16]. In TEAC/ABTS and DPPH, Trolox was employed as reference standard and results are expressed as mg Trolox equivalent (TE) $\mathrm{g}^{-1} \mathrm{DW}$.

\subsection{Statistical Analysis}

All data were analyzed by one-way ANOVA according to a completely randomized design with three replicates. Average values of triplicate determinations \pm standard errors are depicted. Means were compared by Fisher's Least Significant Difference (LSD) at $p$-value $<0.05$.

\section{Results}

\subsection{Germination and Sprout Growth}

The G was over 70\% in three out of five Citrus genotypes, with bitter orange showing the highest value $(90 \%)$ (Table 1$)$ and mandarin the lowest one $(19 \%)$.

Table 1. Total germination \% (G), mean germination time (MGT) and time to reach $50 \%$ germination (TG50), both expressed as days after sowing (DAS), and individual sprout fresh weight and dry matter concentration of five Citrus genotypes. Means \pm standard errors (in brackets) are depicted.

\begin{tabular}{|c|c|c|c|c|c|}
\hline \multirow[b]{2}{*}{ Genotype } & \multicolumn{3}{|c|}{ Seed Germination Indexes } & \multicolumn{2}{|c|}{ Sprout Growth Indexes } \\
\hline & $\begin{array}{c}G \\
(\%)\end{array}$ & $\begin{array}{l}\text { MGT } \\
\text { (DAS) }\end{array}$ & $\begin{array}{c}\text { TG50 } \\
\text { (DAS) }\end{array}$ & $\begin{array}{l}\text { Fresh Weight } \\
\text { (mg) }\end{array}$ & $\begin{array}{c}\text { Dry Matter } \\
\text { Concentration } \\
(\%)\end{array}$ \\
\hline Bitter orange & $90(2)$ & $42(1)$ & $43(1)$ & $28.3(1.9)$ & $20.1(0.7)$ \\
\hline Blonde orange & $72(9)$ & $51(1)$ & $62(5)$ & $22.4(2.5)$ & $20.6(0.5)$ \\
\hline Sweet orange & $58(6)$ & $50(3)$ & $68(4)$ & $23.0(2.6)$ & $21.3(0.5)$ \\
\hline Lemon & $75(5)$ & $35(1)$ & $37(1)$ & $33.5(4.5)$ & $17.5(1.2)$ \\
\hline Mandarin & $19(5)$ & $33(0)$ & N.R. & $18.2(2.2)$ & $20.9(1.4)$ \\
\hline
\end{tabular}

The MGT was about 5 weeks for lemon and mandarin, 6 weeks for bitter orange, and over 7 weeks for sweet and blonde orange. The TG50 was low in lemon and bitter orange (37 and 43 days after sowing, DAS) and quite high in sweet and blonde orange. The fresh weight of sprouts was $25 \mathrm{mg}$ on average, with the highest value in lemon $(34 \mathrm{mg})$ and the lowest in mandarin $(18 \mathrm{mg})$, and the dry matter concentration was similar for all genotypes ( $20 \%$ on average).

\subsection{Total Phenolic Concentration}

The TPC in seeds ranged between $1.2 \mathrm{mg} \mathrm{GAE} \mathrm{g}^{-1} \mathrm{DW}$ for lemon and $2.5 \mathrm{GAE} \mathrm{g}^{-1} \mathrm{DW}$ for bitter orange (Figure 1).

Sprouting always caused an increase of TPC, from 4-fold in bitter orange to 8-fold in blonde orange, as compared with seeds. Thus, TPC in sprouts ranged from $6.8 \mathrm{mg} \mathrm{GAE} \mathrm{g}^{-1} \mathrm{DW}$ in lemon to $11.2 \mathrm{mg} \mathrm{GAE} \mathrm{g}^{-1} \mathrm{DW}$ in blonde orange. 


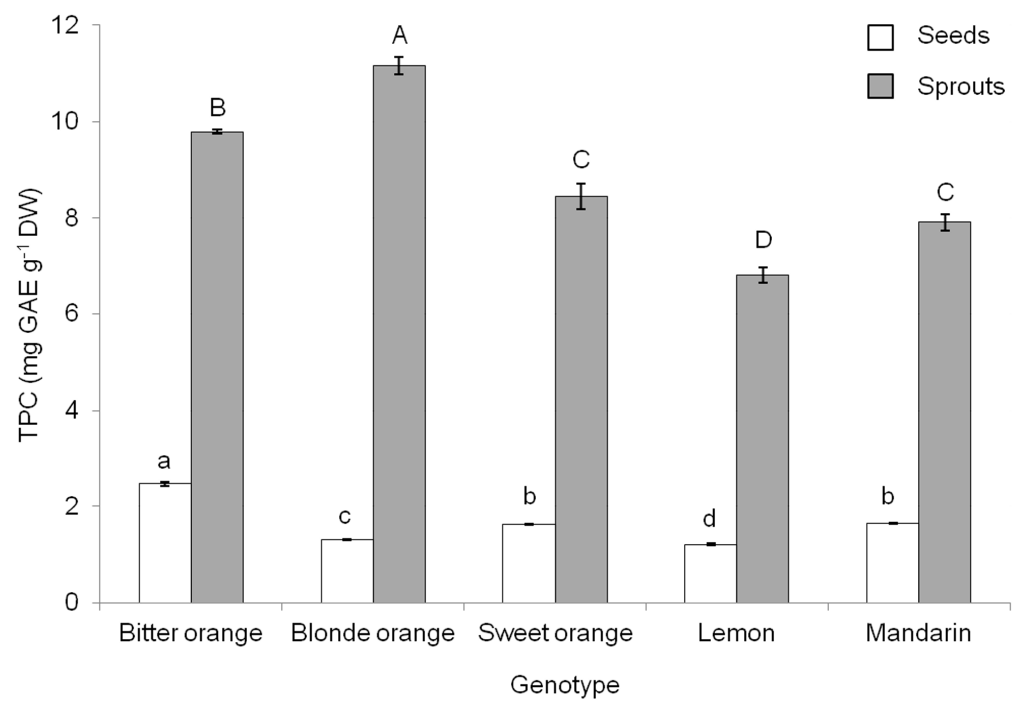

Figure 1. Total phenolic concentration (TPC) (mg gallic acid equivalents (GAE) $\mathrm{g}^{-1}$ dry weight (DW)) in seeds (white) and sprouts (grey) of five Citrus genotypes. Means \pm standard errors (vertical bars) are depicted. Different letters (lower case within seeds; upper case within sprouts) indicate significant differences at $p<0.05$ (Fisher's Least Significant Difference (LSD).

\subsection{Phenolic Acids}

The obtained regression equations and coefficients of correlation ( $>0.9995)$ revealed a good linearity response for the used method. The concentration of PAs varied between genotypes and growth stages (Table 2).

Table 2. Concentrations of single and total free phenolic acids $\left(\mu \mathrm{g} \mathrm{g}^{-1} \mathrm{DW}\right)$ in seeds and sprouts of five Citrus genotypes. Means \pm standard errors are depicted. Different letters (lower case within seeds; upper case within sprouts) indicate significant differences at $p<0.05$ (Fisher's LSD).

\begin{tabular}{|c|c|c|c|c|c|}
\hline \multirow{3}{*}{ Genotype } & \multicolumn{5}{|c|}{ Phenolic Acids ( $\left.\mu \mathrm{g} \mathrm{g}^{-1} \mathrm{DW}\right)$} \\
\hline & \multirow{2}{*}{$\frac{\text { Hydroxybenzoic Acids }}{\text { VA }}$} & \multicolumn{3}{|c|}{ Hydroxycinnamic Acids } & \multirow{2}{*}{ Total } \\
\hline & & $\mathrm{CaA}$ & FA & p-CA & \\
\hline \multicolumn{6}{|l|}{ Seeds } \\
\hline Bitter orange & $3.3(0.2)$ & $4.8(0.2)$ & $3.1(0.2) \mathrm{c}$ & $15.0(0.2) b$ & $26.2(0.2) b$ \\
\hline Blonde orange & NQ & ND & $3.4(0.2) \mathrm{c}$ & $3.1(0.2) \mathrm{c}$ & $6.5(0.2) \mathrm{d}$ \\
\hline Sweet orange & NQ & ND & $8.2(0.5) b$ & $6.5(0.3) c$ & $14.7(0.8) \mathrm{c}$ \\
\hline Lemon & $13.8(1.6)$ & ND & $12.7(0.9)$ a & $30.8(2.4) \mathrm{a}$ & $57.3(4.7)$ a \\
\hline Mandarin & $4.4(0.3)$ & ND & $7.6(0.3) b$ & $6.0(0.2) \mathrm{c}$ & $18.0(0.8) \mathrm{c}$ \\
\hline \multicolumn{6}{|l|}{ Sprouts } \\
\hline Bitter orange & NQ & $6.9(0.2) \mathrm{B}$ & $22.3(0.2) \mathrm{B}$ & $11.6(0.3) \mathrm{B}$ & $40.8(0.3) \mathrm{C}$ \\
\hline Blonde orange & NQ & $2.8(0.3) \mathrm{C}$ & $12.7(0.3) \mathrm{D}$ & $7.1(0.1) \mathrm{D}$ & $22.6(0.4) \mathrm{E}$ \\
\hline Sweet orange & NQ & $12.9(0.3) \mathrm{A}$ & $33.9(0.2) \mathrm{A}$ & $10.2(0.3) \mathrm{C}$ & $57.1(0.3) \mathrm{A}$ \\
\hline Lemon & NQ & ND & $15.1(0.1) \mathrm{C}$ & $32.4(0.5) \mathrm{A}$ & $47.5(0.6) \mathrm{B}$ \\
\hline Mandarin & NQ & $13.5(0.3) \mathrm{A}$ & $9.4(0.2) \mathrm{E}$ & 4.7 (0.3) E & $27.6(0.4) \mathrm{D}$ \\
\hline
\end{tabular}

ND: not detectable $\left(<0.10 \mu \mathrm{g} \mathrm{g}^{-1} \mathrm{DW}\right)$; NQ: not quantifiable; VA: vanillic acid; CaA: caffeic acid; FA: trans-ferulic acid; $p$-CA: $p$-coumaric acid.

In seeds, lemon showed the highest concentration of total PAs and of each single PA except for $\mathrm{CaA}$, which was not detected. The FA and $p$-CA were generally the most represented PAs in all genotypes, while VA and CaA were detected only in some genotypes.

Sprouting generally increased the concentration of total PAs (over 2 times higher than in seeds), except for lemon, where a slight decrease was observed. The highest value of total PAs was observed in sweet orange and the lowest in blonde orange. The increase was observed for any single PA except for VA, which became unquantifiable in all genotypes. In lemon sprouts, $\mathrm{CaA}$ remained unquantifiable as it was in seeds. 


\subsection{Antioxidant Activity}

The antioxidant activity measured as ABTS and DPPH tests is reported in Figure 2.

The antioxidant activity did not differ significantly between genotypes either in seeds or sprouts. However, passing from seeds to sprouts, the antioxidant activity increased for all genotypes. Compared with seeds, the antioxidant activity was on average 6 times higher with the ABTS assay (Figure 2a) and 8 times higher with the DPPH method (Figure 2 b).

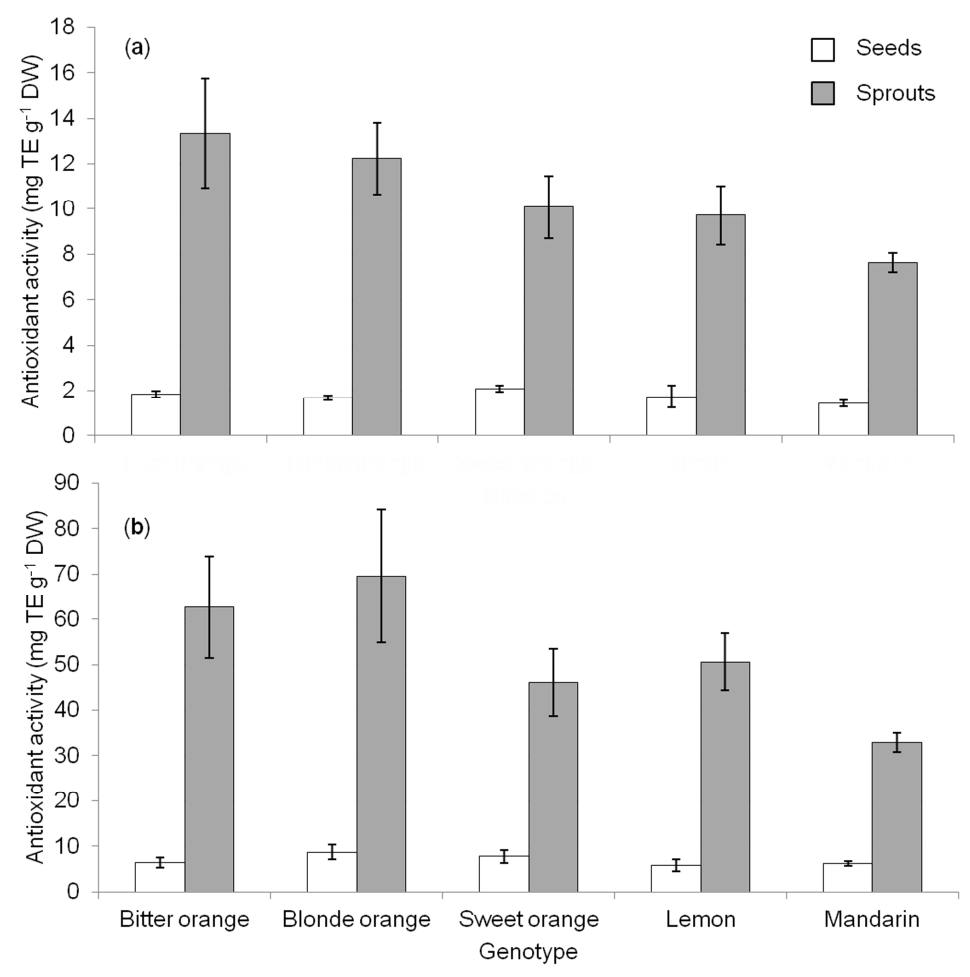

Figure 2. Antioxidant activities measured by 2,2'-azinobis-(3-ethyl-benzothiazoline-6-sulfonic acid) (ABTS) (a) and 2,2-diphenyl-1picrylhydrazyl (DPPH) (b) (mg Trolox equivalent (TE) $\mathrm{g}^{-1} \mathrm{DW}$ ) in seeds (white) and sprouts (grey) of five Citrus genotypes. Means \pm standard errors (vertical bars) are depicted.

\section{Discussion}

The germination of seeds from Citrus genotypes was reported to be generally high when seeds are sown immediately after fruit harvest [7-11], although it may differ among species and genotypes [10]. This fact is hypothesized to be due to excessive desiccation, which might cause membrane disruption [7]. Our $\mathrm{G}$ values for sweet orange, bitter orange, and lemon are in line with results obtained by Zaher-Ara et al. [10]. On the other hand, the $G$ value of mandarin was very low compared with values observed by Hassanein and Azooz [7], but these authors considered different genotypes and harvest seasons. In particular, they reported that for the same harvest season, the fruit ripening time (i.e., green, yellow orange, or dark orange fruits) might affect significantly the germination percentage and the seed vigor. Thus, the low seed germination mayhave been due to the immaturity of embryos and the presence of germination inhibitors, such as abscisic acid (ABA).

Literature on MGT and TG50, as well as on the fresh weight and dry matter concentration of sprouts is not available for most of these species or not comparable due to wide differences in experimental treatments and germination conditions. Prajapati et al. [8] reported a slightly lower TG50 for lime. Extending the comparison to other fruittree species considered for sprouting purposes, the MGT and TG50 observed here were higher than those of pomegranate [4] and comparable to those of olive, if we include the month of stratification necessary for this species [5]. In the case of olive, Falcinelli et al. [5] discussed that the long time needed for stratification and germination appeared 
unsuitable for homemade production of edible sprouts and suggested an alternative use for extraction of food additives and pharmaceutics. Based on the data observed in this experiment, the same could be hypothesized for Citrus sprouts. Moreover, we did not plan any panel test, but our preliminary tasting suggests these sprouts are not suitable for direct eating because they are bitter and astringent (the taste generally attributed to limonoids) [2] and have the quite hard consistency of cotyledons.

The substantial invariance of fresh weight and dry matter concentration of sprouts among Citrus genotypes was expected, since they were all collected just after the cotyledonal stage and, in fact, cotyledon size was similar for all species, as was the seed size.

The TPC of seeds in different Citrus species has been demonstrated to vary with the year [17] and the ripening phase [1]. The values we observed are much higher than those observed in mandarin, orange, and lemon by İnan et al. [17] and in line with those observed in bitter orange and mandarin in seeds from immature fruits but higher than those of seeds from mature fruits [1]. Sprouting was confirmed to increase the TPC, but the increase was not as great as that recorded in pomegranate and olive [4,5]. Moreover, as compared with pomegranate and olive, Citrus species had lower TPC in seeds, confirming that the botanical family/species plays a primary role in affecting the contents of these compounds $[4,5]$. Combining data on germination percentage and individual growth indexes (Table 1) with data on TPC (Figure 1), it was determined that the highest phenolic yield would be achieved with bitter orange.

The phenolic acids detected in seeds were also reported by Moulehi et al. [1] and Bocco et al. [2], with some differences among species. As for TPC, the concentration of any PA in seeds may vary with fruit ripening [1].

The general increase observed in PAs passing from seeds to sprouts is in line with the literature on herbaceous species reviewed by Benincasa et al. [6], while no evidence is available for sprouts from fruittree species. Only in lemon was there a decrease of total PAs, mainly due to the decrease of VA. The contribution from free and bound fractions to total PA increase depends on species and sprouting conditions [6]; for example, in Triticum genotypes, the free fraction increases and the bound one decreases as sprouting goes on $[13,18]$. Indeed, PAs exist as free (i.e., aglycones) and bound (i.e., cell wallbound) forms, which have different bioavailability and health benefits [18]. In particular, dietary intake of free phenolics may be more rapidly absorbed during digestion and released in the body, inhibiting oxidation of low-density lipoprotein (LDL) cholesterol and liposomes, while bound forms may have chemopreventiveactivity against colon cancer [19]. However, it is worth noting that in other sprouts of herbaceous species, it has been found that the antioxidant activity of bound phenolics is lower than that of free phenolics $[20,21]$. For this reason, due to the nutritional relevance and effectiveness of free PAs, in this experiment, we detected only the free fraction of PAs and we cannot say whether VA was turned to the bound form or converted to other compounds. In fact, VA is a precursor of other PAs, such as syringic acid [22], which is present in Citrus species [1].

Since a single method cannot be considered enough for the evaluation of the total antioxidant activity of plant extracts [1], the measure of antioxidant activity in Citrus seeds and sprouts was performed by two different tests involving the reduction of a colored oxidant (ABTS and DPPH) $[4,5]$. Despite differences in magnitude, the two methods revealed a significant increase of antioxidant activity passing from seeds to sprouts (Figure 2a,b), which apparently matchedwith the increase observed for phenolic compounds (Figure 1). Nonetheless, no correlation was found between TPC and the values of DPPH or ABTS, both in seeds and sprouts (data not shown), as previously observed in seeds of other Citrus genotypes [2]. This suggests that other substances, besides phenols, likely play a role as antioxidants and this needs to be further investigated. Literature on antioxidant activity in Citrus seeds is scarce and based on different extraction methods or expressed in different ways [1,2,17], while no literature is available on the antioxidant activity of sprouts. 


\section{Conclusions}

The results indicate that sprouting of Citrus species is feasible; however, it takes several weeks and appears unsuitable for homemade production and direct consumption, in part due to the quite hard consistency of cotyledons and the bitter and astringent taste. On the other hand, the concentration of total phenols and phenolic acids, as well as the antioxidant activity of sprouts were much higher than in seeds. Thus, sprouting Citrus seeds could represent a way to provide a high-value material for extraction of food additives, cosmetics, and pharmaceutics. Regarding this, the highest phenolic yield was achieved with bitter orange, as a result of the highest germination percentage combined with good individual sprout growth and high phenolic concentration.

Author Contributions: Conceptualization, P.B., F.F., and B.F.; methodology, B.F., A.G., S.D. and F.S.; formal analysis, S.D. and A.G.; investigation, all authors; resources, P.B., F.F., A.P., A.G. and F.S.; data curation, A.G., S.D. and B.F.; writing-original draft preparation, P.B. and B.F.; writing-review and editing, all authors; supervision, P.B. and F.F.; project administration, P.B.; funding acquisition, P.B. All authors have read and agreed to the published version of the manuscript.

Funding: This research was funded by the Fondo di Ricerca di Base 2018 of the Dipartimento di Scienze Agrarie, Alimentaried Ambientaliof the Università di Perugia.

Acknowledgments: We gratefully acknowledge Tiziano Caruso of the University of Palermo, Italy for having provided the fruits used in the investigation and Silvano Locchi for technical assistance in the seed lab of the Department of Agricultural, Food, and Environmental Sciences of the University of Perugia, Italy.

Conflicts of Interest: The authors declare no conflict of interest.

\section{References}

1. Moulehi, I.; Bourgou, S.; Ourghemmi, I.; Tounsi, M.S. Variety and ripening impact on phenolic composition and antioxidant activity of mandarin (Citrus reticulate Blanco) and bitter orange (Citrus aurantium L.) seeds extracts. Ind. Crops Prod. 2012, 39, 74-80. [CrossRef]

2. Bocco, A.; Cuvelier, M.E.; Richard, H.; Berset, C. Antioxidant activity and phenolic composition of citrus peel and seed extracts. J. Agric. Food Chem. 1998, 46, 2123-2129. [CrossRef]

3. Malacrida, C.R.; Kimura, M.; Jorge, N. Phytochemicals and antioxidant activity of citrus seed oils. Food Sci. Technol. Res. 2012, 18, 399-404. [CrossRef]

4. Falcinelli, B.; Marconi, O.; Maranghi, S.; Lutts, S.; Rosati, A.; Famiani, F.; Benincasa, P. Effect of genotype on the sprouting of pomegranate (Punicagranatum L.) seeds as a source of phenolic compounds from juice industry by-products. Plant. Food Hum. Nutr. 2017, 72, 432-438. [CrossRef]

5. Falcinelli, B.; Maranghi, S.; Paoletti, A.; Marconi, O.; Rosati, A.; Famiani, F.; Benincasa, P. Sprouting olive (Oleaeuropaea, L.) seeds as a source of antioxidants from residual whole stones. Sci. Hortic. 2018, 240, 558-560. [CrossRef]

6. Benincasa, P.; Falcinelli, B.; Lutts, S.; Stagnari, F.; Galieni, A. Sprouted grains: A comprehensive review. Nutrients 2019, 11, 421. [CrossRef]

7. Hassanein, A.M.; Azooz, M.M. Propagation of Citrus reticulata via in vitro seed germination and shoot cuttings. Biol. Plant. 2003, 47, 173-177. [CrossRef]

8. Prajapati, D.G.; Satodiya, B.N.; Desai, A.B.; Nagar, P.K. Influence of storage period and growing media on seed germination and growth of acid lime seedlings (Citrus aurantifolia Swingle) Cv. Kagzi. J. Pharmacogn. Phytochem. 2017, 6, 1641-1645.

9. Prajapati, D.G.; Satodiya, B.N.; Nagar, P.K. Effect of storage period and growing media on seed germination and physiological attributes of acid lime seedlings (Citrus aurantifolia Swingle) cv. Kagzi. Int. J. Conserv. Sci. 2017, 5, 1945-1948.

10. Zaher-Ara, T.; Boroomand, N.; Sadat-Hosseini, M. Physiological and morphological response to drought stress in seedlings of ten citrus. Trees 2016, 30, 985-993. [CrossRef]

11. Xiong, B.; Ye, S.; Qiu, X.; Liao, L.; Sun, G.; Luo, J.; Dai, L.; Rong, Y.; Wang, Z. Transcriptome analyses of two citrus cultivars (Shiranuhi and Huangguogan) in seedling etiolation. Sci. Rep. 2017, 7, 46245. [CrossRef] [PubMed] 
12. Ellis, R.A.; Roberts, E.H. The quantification of ageing and survival in orthodox seeds. Seed Sci. Technol. 1981, 9, 373-409.

13. Benincasa, P.; Galieni, A.; Manetta, A.C.; Pace, R.; Guiducci, M.; Pisante, M.; Stagnari, F. Phenolic compounds in grains, sprouts and wheatgrass of hulled and non-hulled wheat species. J. Sci. Food. Agric. 2015, 95, 1795-1803. [CrossRef] [PubMed]

14. Singleton, V.L.; Rossi, J.A. Colorimetry of total phenolics with phosphomolybdic-phosphotungstic acid reagents. Am. J. Enol. Viticult. 1965, 16, 144-158.

15. Masaldan, S.; Iyer, V.V. Antioxidant and antiproliferative activities of methanolic extract of Aloe vera leaves in human cancer cell lines. J. Pharm. Res. 2011, 4, 2791-2796.

16. Brand-Williams, W.; Cuvelier, M.E.; Berset, C. Use of a free radical method to evaluate antioxidant activity. LWT-Food Sci. Technol. 1995, 28, 25-30. [CrossRef]

17. İnan, Ö.; Özcan, M.M.; Aljuhaimi, F. Effect of location and Citrus species on total phenolic, antioxidant, and radical scavenging activities of some Citrus seed and oils. J. Food Process. Pres. 2018, 42, e13555. [CrossRef]

18. Hung, V.P.; Hatcher, D.W.; Barker, W. Phenolic acid composition of sprouted wheats by ultra-performanceliquid chromatography (UPLC) and their antioxidant activities. Food Chem. 2011, 126, 1896-1901. [CrossRef]

19. Acosta-Estrada, B.A.; Gutiérrez-Uribe, J.A.; Serna-Saldívar, S.O. Bound phenolics in foods, a review. Food Chem. 2014, 152, 46-55. [CrossRef]

20. Falcinelli, B.; Sileoni, V.; Marconi, O.; Perretti, G.; Quinet, M.; Lutts, S.; Benincasa, P. Germination under moderate salinity increases phenolic content and antioxidant activity in rapeseed (Brassica napusvaroleifera Del.) sprouts. Molecules 2017, 22, 1377. [CrossRef]

21. Ti, H.; Zhang, R.; Zhang, M.; Li, Q.; Wei, Z.; Zhang, Y.; Tang, X.; Deng, Y.; Liu, L.; Ma, Y. Dynamic changes in the free and bound phenolic compounds and antioxidant activity of brown rice at different germination stages. Food Chem. 2014, 161, 337-344. [CrossRef] [PubMed]

22. Heleno, S.A.; Martins, A.; Queiroz, M.J.R.; Ferreira, I.C. Bioactivity of phenolic acids: Metabolites versus parent compounds: A review. Food Chem. 2015, 173, 501-513. [CrossRef] [PubMed]

(C) 2020 by the authors. Licensee MDPI, Basel, Switzerland. This article is an open access article distributed under the terms and conditions of the Creative Commons Attribution (CC BY) license (http://creativecommons.org/licenses/by/4.0/). 